Www.jmscr.igmpublication.org

Impact Factor (SJIF): 6.379

Index Copernicus Value: 79.54

ISSN (e)-2347-176x ISSN (p) 2455-0450

crossrefDOI: https://dx.doi.org/10.18535/jmscr/v6i10.129

Journal Of Medical Science And Clinical Research

IGM Publication

An Official Publication of IGM Publication

\title{
Estimation of Plasma Fibrinogen Levels in Acute Stroke Patients
}

\author{
Authors \\ Dr Perumalla Varun Kumar ${ }^{1}$, Dr Gaddam Srinivas Reddy ${ }^{2}$ \\ ${ }^{1,2}$ Assistant Professor, Dept. of General Medicine, Kamineni Institute of Medical Sciences, Narkatpally, \\ Telangana State, India \\ Corresponding Author \\ Dr Gaddam Srinivas Reddy \\ Email:dr.gsreddy.kims@gmail.com, Mobile: 8897700033
}

\begin{abstract}
Fibrinogen is an acute phase protein, which is produced by Hepatocytes. Human fibrinogen is an independent predictor of coronary heart disease and stroke. Elevated fibrinogen levels are associated with a blood coagulation condition. It is therefore of interest to measure the plasma fibrinogen levels in patients with acute stroke and also to investigate whether these levels increase if the patient has additional risk factors like hypertension, diabetes, and smoking. About 30 patients of acute stroke patients admitted within 24 hours of development of symptoms at Kamineni Institute of Medical Sciences, Telangana were included in the study. Fasting plasma fibrinogen in $\mathrm{mg} / \mathrm{dl}$ was estimated using Clauss method and compared with control group with same age, sex and risk factors. Out of the total 30 patients, mean plasma fibrinogen levels were significantly higher in stroke patients $(455.84 \pm 12.36 \mathrm{mg} / \mathrm{dl})$ when compared to control patients $(282.35 \pm 13.49 \mathrm{mg} / \mathrm{dl})$. In this 26 had ischemic stroke and 4 had hemorrhagic stroke. Fibrinogen levels were significantly higher in males, and it showed increasing levels as the age advances. Hypertension, Smoking, diabetes and obesity also influence levels of plasma fibrinogen.
\end{abstract}

Keywords: Ischemic stroke, Hemorrhagic stroke, Fibrinogen, Diabetes, Hypertension.

\section{Introduction}

Fibrinogen is an important blood coagulation factor and inflammatory factor. Previous studies have shown that fibrinogen levels are strongly associated with the risk of stroke ${ }^{[1]}$. Higher clot burden is related to more severe stroke symptoms and poor outcome ${ }^{[1,2]}$.

In urban India stroke accounts for $1 \%$ mortality of all hospital admissions, $4 \%$ in all medical cases and about $20 \%$ in all disorders of central nervous system $^{[3]}$. Risk factors for stroke are hypertension, atrial fibrillation, carotidstenosis, hyperlipidemia, diabetes, myocardial infarction, atrial myxomas and smoking $^{[4]}$.

Epidemiological observations indicate that high plasma fibrinogen levels strongly correlate with the frequency of two major thrombotic complications of atherosclerosis, stroke as well as myocardial infarction. Thrombosis is increasingly recognized as a central mechanism in stroke and myocardial infarction, and fibrinogen is believed to be involved in events thought to play a major role in thrombosis. Therefore elucidation of the relationship between fibrinogen and thrombosis may strengthen the predictive value of this protein and suggest new 
treatment in management of stroke ${ }^{[5]}$. Hence this study is designed to investigate the association between plasma fibrinogen levels and acute stroke. An objective of this study is to detect plasma fibrinogen levels in patients with acute stroke.

\section{Material and Methods}

The present study was conducted at Kamineni institute of medical sciences, Narketpally from January 2015 to December 2017 after obtaining permission from the hospital ethics committee. This study includes 30 patients presenting with acute stroke as test group and compared with 30 controls not suffering from stroke with matched age, sex and risk factors. Plasma fibrinogen levels in these two groups were estimated. Detailed history will be taken to find out the risk factors such as hypertension, diabetes, smoking and alcohol consumption. Arterial hypertension was diagnosed when its presence was documented in medical records or when at least two readings of blood pressure were $\geq 140 \mathrm{mmHg}$ (systolic) and $\geq 90 \mathrm{mmHg}$ (diastolic) after the acute phase of stroke. The diagnosis of diabetes mellitus was made when (1) the patient had the recognized diabetes mellitus before stroke as written in medical records and/or took hypoglycemic drugs before stroke; (2). A patient was defined as a smoker if there was a history of cigarette smoking during the last 5 years.

Patients presenting with acute stroke within 24 hours of onset of symptoms and patients of acute cerebrovascular accident in whom CT scan shows cerebral infarct or haemorrhage are included in this study. Patients with evidence of uraemia, infection, active hepatic disease, who suffered from myocardial infarction in last three months and patients who have undergone surgery in last three months, were excluded in this study.

Detailed history, clinical examination and relevant laboratory investigations were done as per proforma both in cases and controls. Fasting plasma fibrinogen was estimated in patients and age, sex and risk matched controls. The plasma fibrinogen was measured quantitatively by Clauss method. The kit used was Dade Behring fibrinogen estimation kit by Dade behring marburg gmbh, Marburg, Germany.

\section{Statistical Methods}

For continuous variables like plasma fibrinogen results it depends on their normal distribution by mean standard deviation (SD) and analysis was done by SPSS software.

\section{Results}

This study includes 60 patient aged from 35 to 75 years with mean age of $55.12 \pm 10.65$ years. The maximum numbers of patients were in the age group 50-59. Among 60 patients studied, 40 were Male and 20 were female.

Table 1 Demographic Data

\begin{tabular}{|l|c|c|}
\hline Parameter & Test group & Control group \\
\hline Age in years & $55.35 \pm 10.36$ & $55.68 \pm 11.69$ \\
\hline Sex $(\mathrm{m} / \mathrm{f})$ & $20 / 10$ & $20 / 10$ \\
\hline Height in cms & $155.35 \pm 12.56$ & $154.39 \pm 13.96$ \\
\hline Weight in Kgs & $60.82 \pm 10.52$ & $61.32 \pm 9.53$ \\
\hline
\end{tabular}

Table 2 Age wise distribution of Plasma fibrinogen $((\mathrm{mg} / \mathrm{dl})$ levels

\begin{tabular}{|l|c|c|c|}
\hline Age & Number & $\begin{array}{c}\text { Test group } \\
(\mathrm{mg} / \mathrm{dl})\end{array}$ & $\begin{array}{c}\text { Control group } \\
(\mathrm{mg} / \mathrm{dl})\end{array}$ \\
\hline $30-39$ & 1 & 451 & 260 \\
\hline $40-49$ & 6 & $526.12 \pm 3.25$ & $262.40 \pm 4.32$ \\
\hline $50-59$ & 7 & $623.58 \pm 5.68$ & $284.48 \pm 7.32$ \\
\hline $60-69$ & 10 & $653.82 \pm 8.32$ & $310.42 \pm 6.25$ \\
\hline $70 \&$ above & 6 & $666.87 \pm 5.32$ & $333.23 \pm 7.32$ \\
\hline Total & 30 & $455.84 \pm 12.36$ & $282.35 \pm 13.49$ \\
\hline
\end{tabular}

In all ages when compared with control group the fibrinogen levels were significantly higher in stroke patients. In this, study it was observed that both in control and study population that fibrinogen levels increases as age advances. As age advances the fibrinolytic activity decreases. This decreased fibrinolytic activity is responsible for increased fibrinogen levels as age

Table 3 Mean fibrinogen $(\mathrm{mg} / \mathrm{dl})$ amongst ischemic and hemorrhagic stroke

\begin{tabular}{|l|c|c|c|}
\hline & $\begin{array}{c}\text { Ischemic } \\
\text { Strokes }\end{array}$ & $\begin{array}{c}\text { Hemorrhagic } \\
\text { strokes }\end{array}$ & Control group \\
\hline No of patients & 26 & 04 & 30 \\
\hline Mean (cases ) & $629.77 \pm 12.30$ & $498.33 \pm 10.23$ & $282.35 \pm 13.49$ \\
\hline
\end{tabular}

In the present study patients with ischemic strokes and hemorrhagic strokes had higher fibrinogen 
levels compared to normal individuals which are statistically significant.

Table 4 Plasma fibrinogen levels in risk groups

\begin{tabular}{|l|c|c|c|c|}
\hline Patients & $\begin{array}{c}\text { Test } \\
\text { group } \\
\text { No } \\
\text { effected }\end{array}$ & $\begin{array}{c}\text { Mean } \\
\text { fibrinogen } \\
\mathrm{mg} / \mathrm{dl}\end{array}$ & $\begin{array}{c}\text { Control } \\
\text { group } \\
\text { No } \\
\text { effected }\end{array}$ & $\begin{array}{c}\text { Mean } \\
\text { fibrinogen } \\
\mathrm{mg} / \mathrm{dl}\end{array}$ \\
\hline Hypertensive & 16 & $586.32 \pm 5.36$ & 15 & $296.56 \pm 6.35$ \\
\hline $\begin{array}{l}\text { Non } \\
\text { hypertensive }\end{array}$ & 14 & $525.23 \pm 6.59$ & 15 & $288.45 \pm 8.96$ \\
\hline Smokers & 19 & $583.46 \pm 6.98$ & 21 & $325.23 \pm 7.95$ \\
\hline Non smokers & 11 & $579.58 \pm 6.55$ & 9 & $298.38 \pm 8.24$ \\
\hline Diabetic & 09 & $629.37 \pm 8.59$ & 10 & $328.25 \pm 4.26$ \\
\hline Non diabetics & 21 & $601.69 \pm 10.23$ & 20 & $299.23 \pm 5.42$ \\
\hline Obesity & 19 & $612.30 \pm 8.97$ & 21 & $352.20 \pm 6.54$ \\
\hline Non obesity & 11 & $602.24 \pm 4.32$ & 09 & $348.27 \pm 8.77$ \\
\hline
\end{tabular}

\section{Discussion}

Several researches have examined the relationship between fibrinogen and stroke, on the fields of whether high levels of fibrinogen are related to the prevalence and mortality of stroke $\mathrm{e}^{[2,6]}$.

In the present study the level fibrinogen increased in stroke patients when compared to control group. Fibrinogen is an acute phase protein, which is produced by Hepatocytes. Human fibrinogen is an independent predictor of coronary heart disease and stroke $^{[7]}$. Elevated fibrinogen levels are associated with a blood coagulation condition ${ }^{[8]}$. A lot of evidence suggests that fibrinogen is the mediator in the development of coronary artery thrombi and future cardiac events ${ }^{[9]}$. High levels of fibrinogen are related to stroke severity and increased mortality in one year after stroke and may result in poor functional outcome ${ }^{[6]}$. Patients with lower initial fibrinogen levels had better functional outcomes when adjusting age factors and initial stroke severity $^{[1]}$. Fibrinogen levels seem to be higher in stroke patients compared with the non-stroke patients. Many inflammatory markers will increase after stroke, such as C-reactive protein and D-Dimer levels ${ }^{[6]}$. Inflammatory markers like C-reactive protein, and fibrinogen, are associated with the acute-phase response so as to be associated with risk of recurrent stroke ${ }^{[10]}$. Vascular endothelial injury can activates up regulation of hepatic fibrinogen and initiates coagulation cascade ${ }^{[11]}$.

Mistry PP et $\mathrm{al}^{[3]}$, in their study involving 56 patients admitted in the hospital within 24 hours of onset of symptoms. The levels were found to be raised significantly $(531.73 \pm 74 \mathrm{mg} \%)$ compared to those of the age and sex matched control group $(445.78 \pm 92.28 \mathrm{mg} \%)$. Hazra B et $\mathrm{al}^{[12]}$, in their study involving 33 patients of cerebral thrombosis and 30 patients with cerebral haemorrhage admitted within 24 hours of onset of stroke concluded that the mean plasma fibrinogen concentration in patients of cerebral thrombosis $(378.67 \mathrm{mg} / \mathrm{dl})$ is significantly higher when compared to patients with cerebral haemorrhage $(224.4 \mathrm{mg} / \mathrm{dl})$ and in the control group (216.67). This study also demonstrates an increasing trend of fibrinogen with age. Fibrinogen was increased in females than males. AJ le ${ }^{[13]}$ and TW Maede ${ }^{[14]}$ have shown that fibrinogen level increases with age. Fibrinolytic activity reduces as age advances because of, as age advances there is change in orientation of gpIIa/IIIb receptor causing decreased fibrinolytic activity which accounts for increased plasma fibrinogen levels as age advances. It is likely that mutation accumulation of plasma fibrinogen plays a significant role in the changes of fibrinogen with age. The increase of variance with age is the product of unrepaired evolutional damage in different levels of organization, and the mutations causes increased fibrinogen levels as age advances. They have shown males have higher fibrinogen when compared to females.

This study has shown increased fibrinogen levels in controls amongst smokers as compared to non smokers. Ernst $\mathrm{E}^{[15]}$ has demonstrated that smoking is associated with increased plasma fibrinogen levels. Other studies have demonstrated that in smokers, the plasma fibrinogen elevated because smoking activates lung macrophages which releases IL- $\beta$ which increases fibrinogen synthesis ${ }^{[16]}$, Smoking decreases fibrinolytic activity, smoking causes endothelial damage resulting in activation of coagulation system and release clotting factors.

In this study hypertensive patients had higher fibrinogen than normotensives which was not statistically significant. Several studies had shown fibrinogen levels are higher in hypertensives ${ }^{[13,17]}$. Several plausible mechanisms could explain an observed association between elevated fibrinogen 
levels and hypertension ${ }^{[18]}$. Relation of fibrinogen to increased viscosity and peripheral vascular resistance. Hyperinsulinemia and insulin resistance is common amongst hypertensives and hyperinsulinemia is known to cause decreased fibrinolytic activity. Hence increased fibrinogen levels in hypertensives. Markers of inflammation, such as IL-6 and IL-8 are elevated in hypertension and causes reduced consumption of fibrinogen, thereby contributing to increased plasma fibrinogen in hypertension. Increased platelet activation, increased activity of the coagulation system and decreased function of the fibrinolytic system causes increased fibrinogen.

Most of studies had shown that obese individuals have higher fibrinogen levels ${ }^{[15,18]}$. The mechanisms underlying increased plasma fibrinogen in patients who are over-weight are, there is a positive association between obesity and plasma insulin concentration, hyperinsulinemia thereby stimulates fibrinogen synthesis. It is possible that the interaction between obesity and physical inactivity may promote dyslipidaemia and increased plasma fibrinogen.

In this study diabetics had higher fibrinogen than non diabetics. The exact mechanism of increased fibrinogen levels in diabetics is unknown, possible mechanisms include ${ }^{[19]}$. Insulin stimulates cholesterol synthesis in smooth muscle cells and macrophages of the arterial walls, stimulates the proliferation and migration of smooth muscle cells. It also enhances the formation of fibrinogen. Endothelial dysfunction which is common in diabetics, which causes decreased fibrinolytic activity and hence increased plasma fibrinogen levels. The plasma glucagon concentration is positively related to the plasma fibrinogen concentration. Thus, fibrinogen production is markedly enhanced in diabetic patients, and this alteration is likely to determine the observed hyper fibrinogenemia in these patients.

Hyper glucagonemia may contribute to the increased fibrinogen production. Thus, insulin concentrations may need to be maintained at the lowest attainable level in type 2 diabetes to prevent increased fibrinogen synthesis and concentrations.

The elevated level of inflammatory markers such as CRP or fibrinogen at the beginning of stroke may reflect the burden of atherosclerosis and/or the presence of concomitant risk factors like. g., hypertension, diabetes mellitus, obesity ${ }^{[20]}$.

\section{Conclusion}

In this study, mean plasma fibrinogen levels were significantly higher in stroke patients $(455.84 \pm 12.36)$ when compared to control patients $(282.35 \pm 13.49)$. Fibrinogen levels were significantly higher in males, and it showed increasing levels as the age advances. Hypertension, Smoking, diabetes and obesity also influence levels of plasma fibrinogen.

\section{References}

1. Del Zoppo GJ, Levy DE, Wasiewski WW, et al. Hyper fibrinogenemia and functional outcome from acute ischemic stroke. Stroke 2009:40(5), 1687-1691.

2. Pikija S, Trkulja V, Mutzenbach JS, et al. Fibrinogen consumption is related to intracranial clot burden in acute ischemic stroke: a retrospective hyperdense artery study. J. Transl. Med 2016:14(1), 250.

3. Mistry P, Chawla KP, Rai HP, Jaiswal P. Plasma fibrinogen levels in stroke. J Postgrad Med 1990;36:1-4

4. Smith WS, Johnston SC, Easton JD. Cerebrovascular diseases. In: Kasper DL, Fauci AS, Longo DL, Braunwald E, Hauser SL, Jameson LJ, editors. Harrison's Principles of Internal Medicine. Vol 2. $16^{\text {th }}$ Edn. New York: McGra Hill; 2005.p.23722393

5. Diminno G, Mancini M. Measuring plasma fibrinogen to predict stroke and myocardial infarction. Arteriosclerosis 1990; 10:1-7.

6. Marta Swarowska, Aleksandra Janowska Agnieszka Polczak, Aleksandra Klimkowicz Mrowiec, Joanna Pera, Agnieszka Slowik and Tomasz Dziedzic. The Sustained Increase of Plasma Fibrinogen During 
Ischemic Stroke Predicts Worse Outcome Independently of Baseline Fibrinogen Level. Inflammation. 2014; 37(4): 1142-1147

7. Wang L, Li L, Wang H, Liu J. Study on the influence of oxidative stress on the fibrillization of fibrinogen. Biochem. J 473(23), 4373-4384 (2016).

8. Bielak LF, Klee GG, Sheedy PF 2nd, et al. Association of fibrinogen with quantity of coronary artery calcification measured by electron beam computed tomography. Arterioscler. Thromb. Vasc. Biol 2000:20(9), 2167-2171

9. Koenig W. Fibrinogen in cardiovascular disease: an update. Thromb. Haemost 2003:89(4), 601-609.

10. Welsh P, Lowe GDO, Chalmers J, et al. Associations of Proinflammatory Cytokines With the Risk of Recurrent Stroke. Stroke 2000:39(8), 2226-2230.

11. Di Napoli M, Singh P. Is Plasma Fibrinogen Useful in Evaluating Ischemic Stroke Patients?: Why, How, and When. Stroke 2009:40(5), 1549-1552.

12. Hazra B, Sengupta N, Saha SK, Guha S, Das B, Banerjee AR. A study of plasma fibrinogen level in acute stroke patients in Calcutta. Indian journal of physiology and allied sciences 1997;51:76-80

13. Lee AJ, Lowe GD, Woodward M, Pedoe TH. Fibrinogen in relation to personal history of prevalent hypertension, diabetes, stroke, intermittent claudication, coronary heart disease and family history. The Scottish Heart Health study. Br Heart J 1993; 69:338-342.

14. Meade TW, Chakrabarti R, Haines AP, North WR, Stirling Y. Characteristics affecting fibrinolytic activity and plasma fibrinogen concentration. BMJ 1979; 1:15356.

15. Ernst E. Regional variations in plasma fibrinogen levels. Ann of internal medicine 1991;115(4):329-330.
16. Lip GY, Blann AD, Farooqi IS, Zarifis J, Sagar G, Beevers DG. Sequential alterations in haemorheology, endothelial dysfunction, platelet activation and thrombogenesis in relation to prognosis following acute stroke: The West Birmingham Stroke Project. Blood Coagulation and Fibrinolysis. 2002;13:339347

17. Woo D, Broderick JP. Spontaneous intracerebral hemorrhage: epidemiology and clinical presentation. Neurosurg Clin N Am 2002;13:265-279.

18. Sechi LA, Zingaro L, Catena C, Casaccio D, Marchi SE. Relationship of fibrinogen levels and hemostatic abnormalities with organ damage in hypertension. Hypertension 2000;36:978.

19. Barazzoni R, Zanetti MG. Kiwanuka DE, Carraro P, Tiengo A, Tessari P. Increasedfibrinogen production in type 2 diabetic patients without detectable vascular complications: correlation with plasma glucagon concentrations. The Journal of Clinical Endocrinology and Metabolism 2000;85:3121-3125.

20. Dziedzic T, Slowik A, Szczudlik A. Interleukin-6 and stroke: cerebral ischemia versus nonspecific factors influencing interleukin-6. Stroke. 2003;34:e229-e230. 